\title{
EPs 7630 in acute respiratory tract infections - a systematic review and meta-analysis of randomized clinical trials
}

\begin{abstract}
Objective: We review the efficacy and safety of Pelargonium sidoides preparation EPs 7630 in children, adolescents, and adult patients with acute bronchitis (AB), acute rhinosinusitis (ARS), and acute tonsillopharyngitis (ATP).

Methods: Double-blind, randomized, placebo-controlled trials were eligible for inclusion. Suitable trials were entered into meta-analyses performed separately for each indication. Efficacy analyses were based on change of disease specific symptom scores and on complete remission. Safety was analyzed based on the pooled data from all eligible trials, by comparing the incidence of adverse events in a set of pre-defined system groups between EPs 7630 and placebo.

Results: 13 trials with a total of 3,392 participants were included, 10 of which could be entered into meta-analyses of efficacy (AB: 6/8 trials; ARS: 2/2 trials; ATP: 2/3 trials). In ARS, all trials included adults only, whereas studies in ATP had been conducted with children only. Compared to placebo, the analysis of safety showed slightly higher rates of events belonging to the known spectrum of adverse drug reactions to the herbal product, but risk increases $\geq 1 \%$ could be excluded for all investigated system groups except gastrointestinal disorders and epistaxis. No serious adverse drug reactions were reported in any trial. In the meta-analyses of efficacy, EPs 7630 was superior to placebo in reducing both symptom severity and time until complete recovery for all indications investigated. Significant advantages for the herbal drug were also observed for time until the onset of a meaningful treatment effect, global therapy outcome, and days off work, school, or kindergarten. In AB, efficacy could also be shown for both subsets defined by age.
\end{abstract}

Conclusion: EPs 7630 is an efficacious, safe, and well-tolerated herbal medicine in the management of acute respiratory tract infections such as AB, ARS, and ATP in children, adolescents and adults.

Keywords: pelargonium, acute bronchitis, acute rhinosinusitis, acute tonsillopharyngitis, safety; treatment efficacy
Volume 3 Issue I - 2016

\author{
Heinrich Matthys, 'Walter Lehmacher, ${ }^{2}$ \\ Andrea Zimmermann, ${ }^{3}$ Juliette Brandes, ${ }^{4}$ \\ Wolfgang Kamin ${ }^{5}$ \\ 'Department of Pneumology, University Hospital Freiburg, \\ Germany \\ ${ }^{2}$ Institute of Medical Statistics, Informatics and Epidemiology, \\ University of Cologne, Germany \\ ${ }^{3}, 4$ Department of Clinical Research, Dr.Willmar Schwabe \\ $\mathrm{GmbH} \&$ Co. KG, Germany \\ ${ }^{5}$ Clinic for Pediatrics, Evangelic Hospital Hamm, Germany
}

\begin{abstract}
Correspondence: Heinrich Matthys, Medical Director emeritus, Department of Pneumology, University Hospital Freiburg, Hochrüttestraße 17, 791 I7 Freiburg, Germany, Tel +4976I-62822, Fax +49 76I 6008580, Email hmatthys@t-online.de
\end{abstract}

Received: December 14, 2015 | Published: February 18, 2016
Abbreviations: AB, acute bronchitis; AE, adverse event; ARS, acute rhinosinusitis; ATP, acute tonsillopharyngitis; BSS, bronchitis severity scale; CI, confidence interval; IMOS, integrative medicine outcome scale; ISRCTNm, international standard randomized controlled trial number; MEDLINE, medical literature analysis and retrieval system online; RTI, respiratory tract infection; SSS, sinusitis severity score; TSS, tonsillitis severity score

\section{Introduction}

Acute respiratory tract infections (RTIs) are the most common diseases in children and adults. ${ }^{1-4}$ It has been estimated that adults suffer from 2-3 such infections per year, ${ }^{5}$ and although these conditions are often trivial, they may cause significant impairment in quality of life and may interfere with essential activities of daily living. ${ }^{6}$ Therefore their economic impact through decreased productivity and time lost from work or school, visits to health-care providers, and the amount of drugs prescribed, is enormous. ${ }^{2,7,8}$
The management of trivial RTIs is complicated by the confusing terminology that has arisen to define their anatomic locations, while ignoring their usually diffuse nature. As such, the everyday use of the term 'acute respiratory tract infection' has come to encompass multiple and not necessarily better defined clinical entities including acute rhinopharyngitis (common cold), acute bronchitis (AB), acute rhinosinusitis (ARS), and acute tonsillopharyngitis (ATP). ${ }^{5-9}$ It is therefore not surprising that acute RTIs are often associated with similar upper respiratory tract symptoms such as coughing or hoarseness as well as with comparable general symptoms like headache, limb or muscle pain, and fever.

Although it is estimated that at least $90 \%$ of trivial RTIs have a viral etiology, ${ }^{10-12}$ the majority of cases is nevertheless treated with antibiotics which may be efficacious in bacterial, but not in viral infections. ${ }^{13,14}$ Inappropriate antibiotic treatment is, however, not beneficial to the patient, may give rise to disturbing side effects and increase antibiotic resistance rates, and causes unnecessary costs 
to the healthcare system. ${ }^{15,16}$ Therefore, efficacious alternatives to antibiotic treatment have gained interest during recent years, and it is of utmost importance to evaluate the evidence for the efficacy and safety of alternative treatment options.

EPs 7630 is a herbal drug preparation from the roots of Pelargonium sidoides, which has been approved for the treatment of RTIs in several countries in Asia, Europe, Australia as well as in Central and South America. The drug is available in both tablet and liquid forms. Pharmacological activities of EPs 7630 and several of its isolated constituents, such as moderate direct antibacterial and antiviral action and notable immune-modulatory capabilities, have been demonstrated in in-vitro-evaluations: ${ }^{17}$ Immune-modulatory activities are mediated mainly by the release of tumor necrosis factor $\alpha$ and nitric oxides, the stimulation of interferon- $\beta$, and an increase in natural killer cell activity. ${ }^{18-21}$ Biological activities also observed during in-vitro experiments include an improved phagocytosis, oxidative burst and intracellular killing by human peripheral blood phagocytes, and an inhibition of the interaction between group-A streptococci and host epithelia ${ }^{22,23}$ as well as increased stress resistance. ${ }^{24}$ Moreover, EPs 7630 was found to be a potent HIV-1 attachment inhibitor ${ }^{25}$ and to interfere with the replication of seasonal influenza A virus strains (H1N1, H3N2), respiratory syncytial virus, human coronavirus, parainfluenza virus, and coxsackie virus. ${ }^{26}$ Antiinfluenza virus activity of the herbal extract was also confirmed in an animal model. ${ }^{27}$ These antiviral effects may contribute to the efficacy of EPs 7630 in RTIs.

Results from a systematic review and meta-analysis of 6 clinical trials investigating treatment with EPs 7630 in $\mathrm{AB}^{28,29}$ have already shown the effectiveness of the herbal extract in this indication. Timmer et al., ${ }^{30}$ performed a systematic review and meta-analysis of EPs 7630 for acute RTIs in which 10 double-blind, randomized clinical trials were selected for inclusion. This work also shows that EPs 7630 is effective in patients with $\mathrm{AB}$, however, all data of clinical trials in the indication ATP were not analyzed until now. In order to present the complete clinical evidence with respect to efficacy and tolerability of EPs 7630 in AB, ARS and ATP, a systematic review and metaanalysis of the clinical efficacy and tolerability of EPs 7630 in these 3 indications was performed including data from a total of 13 published or previously unpublished randomized, placebo-controlled clinical trials. The treatment comparisons are based on the outcome measures pre-specified in the original study protocols and also on measures of treatment response related to complete symptom recovery.

\section{Material and methods}

\section{Search strategy}

Studies were identified from clinical trial registries (ISRCTN; Clintrials.gov), medical literature (MEDLINE) and the European Medicines Agency's assessment report on Pelargonium sidoides, ${ }^{31}$ the latter of which was based on both published and otherwise unpublished data, using the search term 'EPs 7630'. Eligible studies had to be randomized, double-blind, placebo-controlled, therapeutic trials with EPs 7630 in the indications of AB, ARS, and ATP reported by May 2014.

\section{Interventions}

EPs 7630 is a herbal drug preparation from the roots of Pelargonium sidoides (1:8-10), extraction solvent: ethanol $11 \%(\mathrm{w} / \mathrm{w})$. The recommended daily doses of liquid solution are $3 \times 10$ drops for young children aged between 1-5years, $3 \times 20$ drops for children aged between 6-12years, and 3x30 drops for adults and adolescents over the age of 12 years. For the tablet formulation the recommended daily dose for patients over 12years of age is $3 \times 1$ tablets, each containing $20 \mathrm{mg}$ of the herbal extract, corresponding to the quantity contained in 30 drops of the liquid solution.

\section{Outcome measures}

The primary outcome measures of treatment efficacy specified prospectively in the protocols of the included trials were indication specific symptom scores for which the change between baseline and a pre-defined point in time was evaluated. All scores were computed by adding up the intensity ratings of disease specific symptoms provided on 4- or 5-point verbal rating scales.

In $\mathrm{AB}$, the Bronchitis Severity Scale (BSS) ${ }^{32-34}$ included intensity ratings of the symptoms coughing, sputum production, rales/rhonchi at auscultation, chest pain during coughing, and dyspnea. In children aged 6years and younger, sputum production and chest pain during coughing could not be reliably assessed and were thus omitted from the calculation of the BSS total score. Our meta-analyses assessed changes between baseline and treatment end (day 7) as well as the percentage of patients with complete recovery of symptoms.

A Sinusitis Severity Score (SSS) computed as the sum of the intensity ratings for headache, maxillary pain, worsening of maxillary pain when bending forward, percussion or pressure on maxillary, nasal obstruction, purulent nasal secretion, and purulent nasal discharge in the middle meatus or purulent postnasal discharge was used to assess symptom severity in the trials in the indication of ARS. Our metaanalyses investigated changes between baseline and treatment day 7 as well as the percentage of patients with complete recovery of symptoms.

For ATP, the intensity ratings for difficulty in swallowing, sore throat, salivation, erythema, fever, as well as coating left and right on the tonsils (if assessed) were added up to obtain a Tonsillitis Severity Score (TSS). We investigated the change between baseline and treatment day 4 as well as the percentage of patients with complete recovery of symptoms.

In addition to these scores, efficacy was assessed for all indications utilizing the investigator rated, 1-item Integrative Medicine Outcomes Scale (IMOS) ${ }^{35}$ as well as time until onset of treatment effect, the percentage of patients still off work, school or kindergarten on the day of the primary endpoint assessment, and amount of paracetamol used. Tolerability was assessed based on adverse events.

\section{Ethics}

All primary trials included into this review were planned, executed and analyzed under consideration of the principles of Good Clinical Practice and the Declaration of Helsinki.

The study protocols and other required study documents were submitted to the respective independent ethics committee and regulatory authorities for approval. All participants in the studies gave their informed consent.

\section{Statistics}

For continuous outcomes, meta-analyses of treatment efficacy were performed by computing the difference between the mean values of the treatment groups and the associated $95 \%$ confidence 
intervals on their original scale. Discrete, ordinal outcome measures like the IMOS were processed like continuous outcomes for the sake of illustration. Meta-analyses of binary outcomes were based on risk ratios and their $95 \%$ confidence intervals. Heterogeneity between the primary trials was assessed using the I2 statistic. For comparability with the Cochrane Review on Pelargonium sidoides, ${ }^{30}$ random effects models were computed in case of I $2>5 \%$, and fixed effect models were used otherwise. Review Manager (RevMan) Version 5.2 software ${ }^{36}$ was used for all meta-analyses. Treatment differences were considered descriptively significant if the $95 \%$ confidence interval of the point estimate did not include the value of 0 for differences between means or the value of 1 for risk ratios.

The analysis of safety was based on pooled data from all eligible trials. AEs observed during the analyzed studies and listed in the Summary of Product Characteristics of the marketed product as potential unwanted effects were assigned to system groups which reflect adverse drug reactions that may occur seldom (i.e., in 1-10 patients out of 10,000 exposed) or occasionally (i.e., in 1-10 patients out of 1,000 exposed) during treatment with EPs 7630 (gastrointestinal complaints, hypersensitivity reactions, nasal bleeding, gingival bleeding, and liver associated events). Events were considered to be potentially related if a causal relationship to the blinded investigational treatment could not be excluded. $95 \%$ confidence intervals for the observed rates within the treatment groups were determined based on pooled data from all eligible trials using Wilson's score method $\left(\right.$ method $3 \mathrm{in}^{37}$ ). Confidence intervals for event rate differences were computed using the method based on Wilson's score method for the single proportion, without continuity correction $\left(\operatorname{method} 10 \mathrm{in}^{38}\right)$.

\section{Results}

\section{Primary trials, participants}

Thirteen studies were identified and met our criteria for inclusion. Eight eligible studies investigated the efficacy of EPs 7630 in AB, 2 in ARS, and 3 in ATP. Meta-analyses of efficacy were based on the pre-defined analysis data set of the original studies for the primary efficacy analysis. Our review is based on the data of a total of 3,392 patients (EPs 7630: 2,006, placebo: 1,386). Of these patients, 2,227 participated in studies designed for adults and 1,165 were included into studies for children and adolescents.

\section{Acute bronchitis}

Five placebo-controlled studies included into our review, no. 1-5 in Table 1, assessed the efficacy and safety of EPs 7630 in a total of 1,852 adults (EPs 7630 1,133; placebo 719). In studies no. 2 and 4 , differences between the drop-out patterns of patients randomized to EPs 7630 or placebo were observed, as a substantial number of patients in the placebo groups terminated the study prior to day 7 due to lacking efficacy. To obtain a conservative estimate of the treatment effect, these studies were excluded from the meta-analysis of treatment efficacy, but they were included in a sensitivity analysis with all 5 studies (data not shown), which fully confirmed the results of the meta-analyses presented below.

Table I Characteristics of primary trials-acute bronchitis

\begin{tabular}{|c|c|c|c|c|c|}
\hline \multirow{2}{*}{$\begin{array}{l}\text { Study, } \\
\text { reference }\end{array}$} & \multirow{2}{*}{ Patients } & \multirow{2}{*}{$\begin{array}{l}\text { Treatment duration, } \\
\text { daily dose }\end{array}$} & \multirow{2}{*}{$\begin{array}{l}\text { Design and primary efficacy } \\
\text { outcome measure }\end{array}$} & \multicolumn{2}{|l|}{ Number of patients } \\
\hline & & & & EPs 7630 & Placebo \\
\hline $1^{43}$ & Adults & $\begin{array}{l}7 \text { days: } \\
3 * 30 \mathrm{drops} / \mathrm{d}\end{array}$ & $\begin{array}{l}\text { Double-blind, randomized } \\
\text { Change of BSS-total score, day } 7 \text { vs. } \\
\text { baseline }\end{array}$ & 64 & 60 \\
\hline $2^{44}$ & Adults & $\begin{array}{l}7 \text { days: } \\
3 * 30 \mathrm{drops} / \mathrm{d}\end{array}$ & $\begin{array}{l}\text { Double-blind, randomized } \\
\text { Change of BSS-total score, day } 7 \text { vs. } \\
\text { baseline }\end{array}$ & 233 & 235 \\
\hline $3^{45}$ & Adults & $\begin{array}{l}7 \text { days: } \\
3 * 30 \mathrm{drops} / \mathrm{d}\end{array}$ & $\begin{array}{l}\text { Double-blind, randomized } \\
\text { Change of BSS-total score, day } 7 \text { vs. } \\
\text { baseline }\end{array}$ & 108 & 109 \\
\hline $4^{46}$ & Adults & $\begin{array}{l}\text { I } 4 \text { days: } \\
3 * 30 \text { or } 3 * 45 \text { drops } / \mathrm{d}\end{array}$ & $\begin{array}{l}\text { Double-blind, randomized } \\
\text { Change of BSS-total score, day } 7 \text { vs. } \\
\text { baseline }\end{array}$ & $\begin{array}{l}3 * 30: 214 \\
3 * 45: 210\end{array}$ & $\begin{array}{l}3 * 30: 106 \\
3 * 45: 107\end{array}$ \\
\hline $5^{47}$ & Adults & $\begin{array}{l}7 \text { days: } \\
3 * 10,3 * 20 \text {, or } \\
3 * 30 \mathrm{mg} / \mathrm{d} \text { (tablets) }\end{array}$ & $\begin{array}{l}\text { Double-blind, randomized dose-finding } \\
\text { study } \\
\text { Change of BSS-total score, day } 7 \text { vs. } \\
\text { baseline }\end{array}$ & $\begin{array}{l}3 * 10: 102 \\
3 * 20: 101 \\
3 * 30: 101 \text { (safety) } / 100 \\
\text { (efficacy) }\end{array}$ & 102 \\
\hline $6^{48}$ & $\begin{array}{l}\text { Children between } \\
\text { I and I8years }\end{array}$ & $\begin{array}{l}7 \text { days: } \\
\text { Age I-6: } 3 * 10 \mathrm{drops} / \mathrm{d} \\
\text { Age } 7-12: 3 * 20 \mathrm{drops} / \mathrm{d} \\
\text { Age }>12: 3 * 30 \mathrm{drops} / \mathrm{d}\end{array}$ & $\begin{array}{l}\text { Double-blind, randomized } \\
\text { Change of BSS-total score, day } 7 \text { vs. } \\
\text { baseline }\end{array}$ & 103 & 97 \\
\hline $7^{49}$ & $\begin{array}{l}\text { Children between } \\
6 \text { and I8years }\end{array}$ & $\begin{array}{l}7 \text { days: } \\
3 * 10,3 * 20 \text { or } \\
3 * 30 \mathrm{mg} / \mathrm{d} \text { (tablets) }\end{array}$ & $\begin{array}{l}\text { Double-blind, randomized dose-finding } \\
\text { study Change of BSS-total score, day } 7 \text { vs. } \\
\text { baseline }\end{array}$ & $\begin{array}{l}3 * 10: 101 \text { (safety) / I00 } \\
\text { (efficacy) } \\
3 * 20: 99 \\
3 * 30: 99\end{array}$ & 101 \\
\hline
\end{tabular}




\begin{tabular}{|c|c|c|c|c|c|}
\hline \multirow{2}{*}{$\begin{array}{l}\text { Study, } \\
\text { reference }\end{array}$} & \multirow{2}{*}{ Patients } & \multirow{2}{*}{$\begin{array}{l}\text { Treatment duration, } \\
\text { daily dose }\end{array}$} & \multirow{2}{*}{$\begin{array}{l}\text { Design and primary efficacy } \\
\text { outcome measure }\end{array}$} & \multicolumn{2}{|c|}{ Number of patients } \\
\hline & & & & EPs 7630 & Placebo \\
\hline $8^{50}$ & $\begin{array}{l}\text { Children between } \\
\text { I and I8years }\end{array}$ & $\begin{array}{l}7 \text { days: } \\
\text { Age I-6: } 3 * 10 \text { drops } / \mathrm{d} \\
\text { Age } 7-12: 3 * 20 \mathrm{drops} / \mathrm{d} \\
\text { Age }>12: 3 * 30 \mathrm{drops} / \mathrm{d}\end{array}$ & $\begin{array}{l}\text { Double-blind, randomized } \\
\text { Change of BSS-total score, day } 7 \text { vs. } \\
\text { baseline }\end{array}$ & III & 109 \\
\hline
\end{tabular}

Three eligible trials, no. 6-8 in Table 1, investigated the efficacy of EPs 7630 in a total of 820 children and adolescents (age 1-18years; EPs 7630 513; placebo 307) with $\mathrm{AB}$ and were entered into metaanalyses of efficacy. Separate efficacy analyses were performed for children between 1 and 5 (included into studies no. 6 and 8 only) and between 6 and 18years of age.

Trials no. 5 and 7 were parallel-group dose finding studies investigating tablets containing 10,20, and 30mg of EPs 7630 . For comparability with the studies investigating the liquid medication form, only the patients treated with $20 \mathrm{mg}$ tablets were considered in our meta-analyses of treatment efficacy whereas all patients treated with any dose of EPs 7630 were analyzed for safety.

\section{Acute rhinosinusitis}

For the indication of ARS, 2 placebo-controlled studies in adults (375 patients; EPs 7630 187, placebo 188) were eligible, the main characteristics of which are shown in Table 2. In study no. 9, a disproportionally high premature withdrawal rate was observed in the placebo group due to lack of efficacy. To obtain a conservative estimate of the treatment effect, the meta-analyses were therefore performed based on the results obtained at day 7 , which was also the date for the confirmatory analysis.

Table 2 Characteristics of primary trials-acute rhino sinusitis

\begin{tabular}{|c|c|c|c|c|c|}
\hline \multirow{2}{*}{ Study, Reference } & \multirow{2}{*}{ Patients } & \multirow{2}{*}{$\begin{array}{l}\text { treatment duration, } \\
\text { daily dose }\end{array}$} & \multirow{2}{*}{$\begin{array}{l}\text { Design and primary efficacy outcome } \\
\text { measure }\end{array}$} & \multicolumn{2}{|c|}{ Number of patients } \\
\hline & & & & EPs 7630 & Placebo \\
\hline $9^{51}$ & Adults & $\begin{array}{l}\text { 2I days: } \\
3 * 60 \mathrm{drops} / \mathrm{d}\end{array}$ & $\begin{array}{l}\text { Double-blind, randomized } \\
\text { Change of SSS ( } 6 \text { items), day } 7 \text { vs. baseline }\end{array}$ & 136 & 136 \\
\hline $10^{52}$ & Adults & $\begin{array}{l}21 \text { days: } \\
3 * 60 \text { drops/d } \\
\text { (+8-week observational phase) }\end{array}$ & $\begin{array}{l}\text { Double-blind, randomized } \\
\text { Change of SSS ( } 6 \text { items), day } 7 \text { vs. baseline }\end{array}$ & 51 & 52 \\
\hline
\end{tabular}

\section{Acute tonsillopharyngitis}

Three trials were eligible in the indication of ATP, all of which were performed in children between 6 and 10years of age (Table 3; total number of participants 345; EPs 7630 173, placebo 172). Study no. 11 was excluded from the meta-analyses of efficacy because of an uncommon dosing scheme. Meta-analyses were therefore performed based on studies no. 12 and 13 only.

Table 3 Characteristics of primary trials-acute tonsillopharyngitis

\begin{tabular}{|c|c|c|c|c|c|}
\hline \multirow{2}{*}{$\begin{array}{l}\text { Study, } \\
\text { Reference }\end{array}$} & \multirow{2}{*}{ Patients } & \multirow{2}{*}{$\begin{array}{l}\text { Treatment Duration, } \\
\text { Daily Dose }\end{array}$} & \multirow{2}{*}{$\begin{array}{l}\text { Design And Primary Efficacy } \\
\text { Outcome Measure }\end{array}$} & \multicolumn{2}{|c|}{$\begin{array}{l}\text { Number of } \\
\text { Patients }\end{array}$} \\
\hline & & & & EP & OPlacebo \\
\hline $11^{53}$ & $\begin{array}{l}\text { Children between } 6 \text { and } \\
\text { IOyears }\end{array}$ & $\begin{array}{l}6 \text { days: } \\
\text { Days I-2: up to } \\
\text { I2*20 drops/d } \\
\text { Days } 3-6: 3 * 20 \text { drops/d }\end{array}$ & $\begin{array}{l}\text { Double-blind, randomized } \\
\text { Response:TSS ( } 7 \text { symptoms }) \leq 4 \text { points } \\
\text { at day } 4\end{array}$ & 40 & 38 \\
\hline $12^{54}$ & $\begin{array}{l}\text { Children between } 6 \text { and } \\
\text { IOyears }\end{array}$ & $\begin{array}{l}6 \text { days: } \\
3 * 20 \mathrm{drops} / \mathrm{d}\end{array}$ & $\begin{array}{l}\text { Double-blind, randomized } \\
\text { Change of TSS ( } 5 \text { symptoms), day } 4 \text { vs. } \\
\text { baseline }\end{array}$ & 60 & 64 \\
\hline $13^{55,56}$ & $\begin{array}{l}\text { Children between } 6 \text { and } \\
\text { lOyears }\end{array}$ & $\begin{array}{l}6 \text { days: } \\
3 * 20 \mathrm{drops} / \mathrm{d}\end{array}$ & $\begin{array}{l}\text { Double-blind, randomized } \\
\text { Change of TSS ( } 5 \text { symptoms) day } 4 \text { vs. } \\
\text { baseline }\end{array}$ & 73 & 70 \\
\hline
\end{tabular}




\section{Safety}

The results of the analysis of adverse events based on the system groups mentioned in the Summary of Product Characteristics of the marketed product containing EPs 7630 are shown in Table 4. Compared to placebo, the patients treated with EPs 7630 were at an increased risk of gastrointestinal complaints (any causal relationship: point estimate for the risk difference to placebo $+2.8 \%$, upper limit of $95 \%$ confidence interval $+4.1 \%$; potentially related events: $+1.7 \%$ and $+2.7 \%$ ) as well as of epistaxis (any causal relationship only: $+0.6 \%$ and $+1.1 \%$ ). For all other system groups investigated, the incidence rates of adverse events under EPs 7630 were similar to those in patients treated with placebo, with point estimates for the risk difference not exceeding $+0.5 \%$ and the upper limit of the associated $95 \%$ confidence intervals not exceeding $+1.0 \%$. No serious adverse reactions to EPs 7630 were reported in any of the trials.

Table 4 Incidence of adverse events based on pooled data from I 3 double-blind, placebo controlled trials- number (\%) of patients and $95 \%$ confidence intervals.

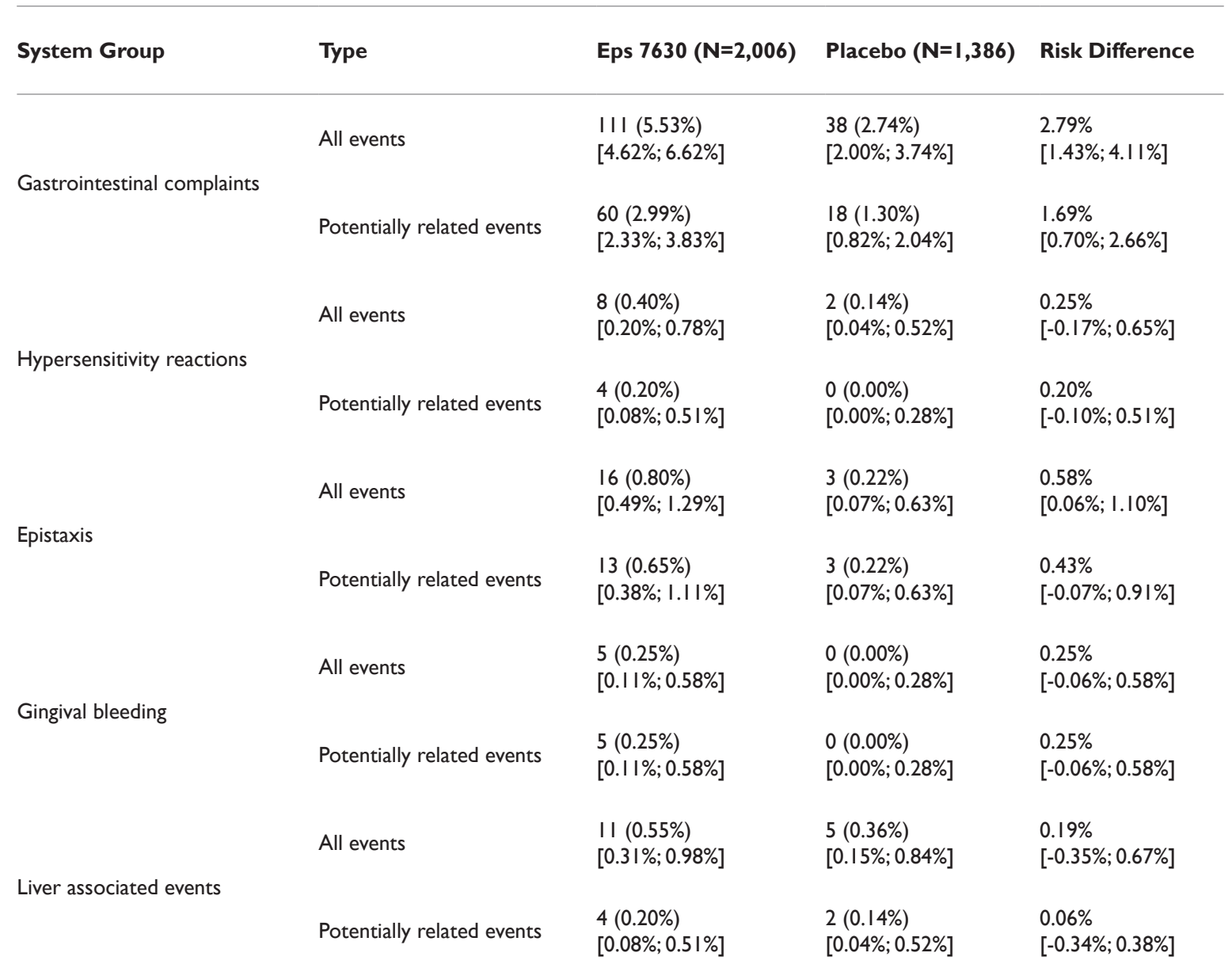

\section{Efficacy: Acute bronchitis}

According to our meta-analyses, EPs 7630 was superior to placebo in reducing the BSS total score between baseline and treatment end at day 7 (Figure 1). These applied to adults as well as to children between 1 and 5 and between 6 and 18years of age (although the primary trials performed in children were not powered to demonstrate efficacy within subgroups). Significant differences favoring EPs 7630 were also observed for complete symptom recovery at day 7 in all subgroups defined by age (Figure 2). The recovery rate under EPs 7630 exceeded that in the placebo group by factor 6 for adults and by more than factor 4 in children and adolescents.

All other outcome measures included into our meta-analyses in the indication of $\mathrm{AB}$ are presented in Table 5 in an abbreviated format. EPs 7630 was significantly superior to placebo in all investigated age subsets for symptom recovery from coughing and sputum production, showed a shorter time until the onset of a meaningful treatment effect and was associated with a shorter disease-related period off work, school, or kindergarten. Moreover, the over-all clinical outcome according to the IMOS was more favorable in patients treated with the herbal drug. In adults EPs 7630 did not reduce paracetamol use to an extent significant on the $5 \%$-level. Children and adolescents, on the other hand, used less paracetamol when treated with EPs 7630, with significant differences versus placebo in the subset under 6years of age.

\section{Efficacy:Acute rhinosinusitis}

Figure 3 and Figure 4 show that EPs 7630 was superior to placebo in reducing the cardinal symptoms of ARS already during the initial 7 out of a total of 21 scheduled days of treatment. Complete subsidence of symptoms at day 7 was observed in 6/187 patients treated with the herbal drug (all from study no. 9) and in none in the placebo group. 
The results for the SSS total score were fully supported by those for the remaining outcome measures investigated, with significant advantages for EPs 7630 with regard to time until the onset of a perceived treatment effect, time off work, and global clinical outcome according to the IMOS (Table 6). For complete recovery from cardinal symptoms of headache and nasal discharge at day 7 the $95 \%$ confidence intervals for the risk ratios against placebo included the value of 1 although the point estimates indicated 4.6-fold and 19-fold higher recovery rates for the herbal drug. The large variability of the data for these symptoms was attributable to the fact that study no. 9 exhibited a significant advantage of EPs 7630 over placebo already at day 7 whereas for some symptoms significant advantages in study no. 10 were only observed later during the trial. At day $21,31 / 51$ patients exposed to EPs 7630 in study no. 10 and 5/52 patients in the placebo group were in full remission with respect to the complete recovery of all sinusitis specific symptoms (rate ratio: $6.3 ; 95 \%$ CI: $[2.7 ; 15.0]$ ). Paracetamol consumption was moderately lower under EPs 7630 , but the difference to placebo was non-significant on the $5 \%$-level.

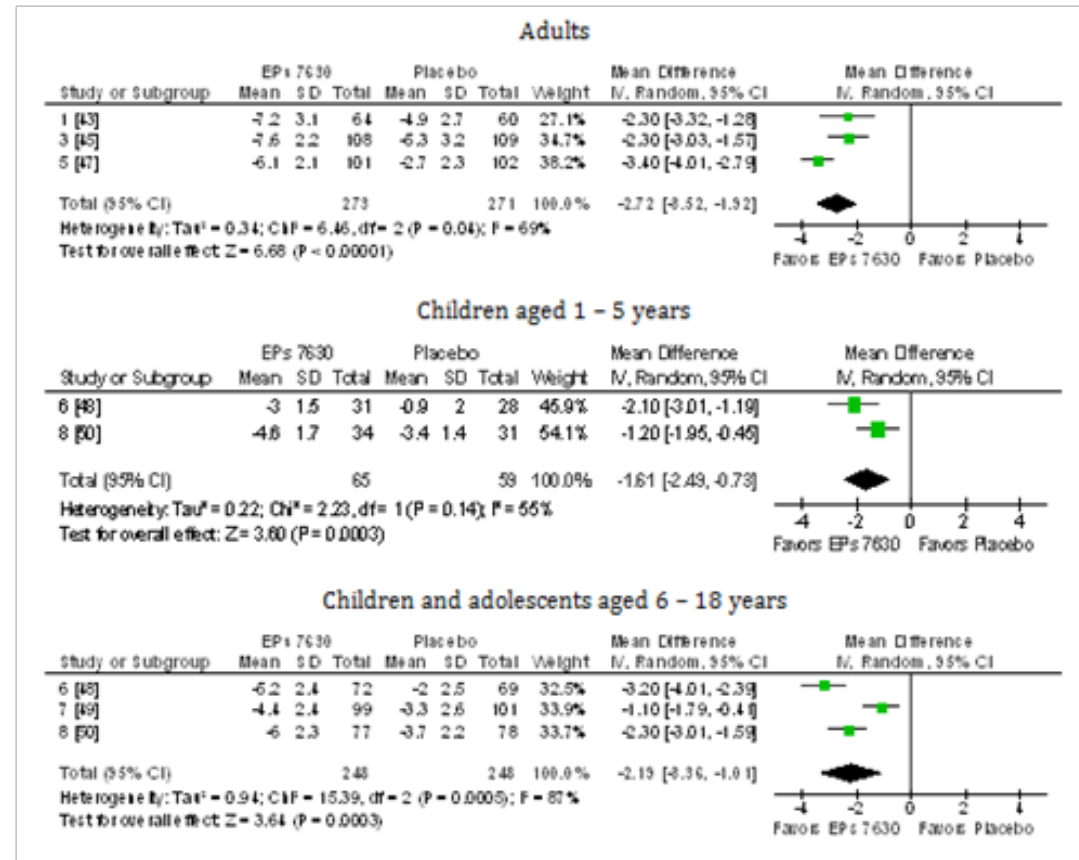

Figure I Meta-analysis of change of BSS total score between baseline and treatment day 7 in patients with acute bronchitis.

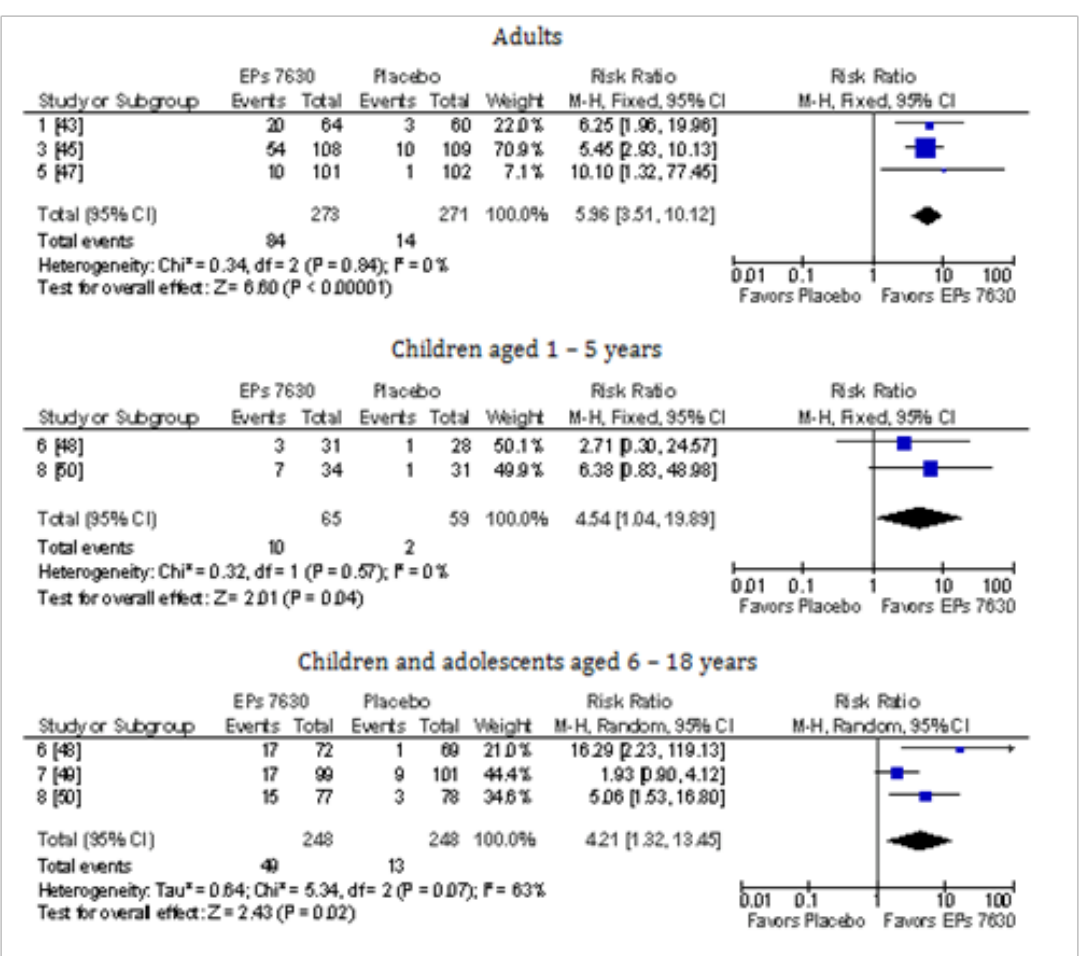

Figure 2 Meta-analysis of complete recovery of all symptoms assessed with the BSS until day 7 in patients with acute bronchitis. 
EPs 7630 in acute respiratory tract infections - a systematic review and meta-analysis of randomized

Table 5 Meta-analysis results for outcome measures in acute bronchitis based on studies no. I, 3 and 5 (adults), 6 and 8 (children aged I-5), and 6, 7, and 8 (children and adolescents aged 6-18)

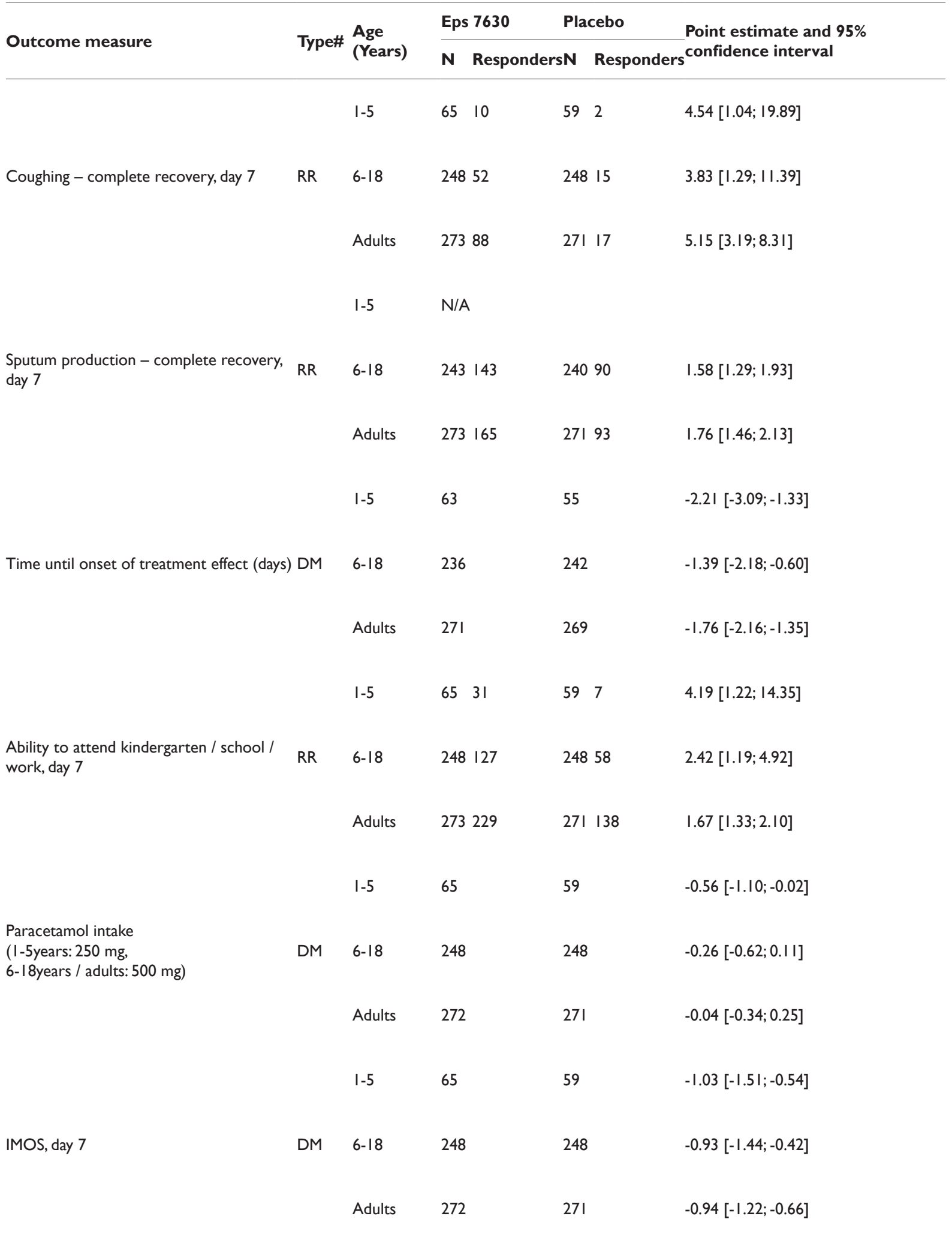

\#DM-difference of means; values $<0$ favor EPs 7630

RR - risk ratio; values >I favor EPs 7630 
Table 6 Meta-analysis results for outcome measures in acute rhino sinusitis based on studies no. 9 and 10

\begin{tabular}{|c|c|c|c|c|c|c|}
\hline \multirow{2}{*}{ Outcome measure } & \multirow{2}{*}{ Type\# } & \multicolumn{2}{|c|}{ Eps 7630} & \multicolumn{2}{|c|}{ Placebo } & \multirow{2}{*}{$\begin{array}{l}\text { Point estimate and } 95 \% \text { confidence } \\
\text { interval }\end{array}$} \\
\hline & & $\mathbf{N}$ & Responders & $\mathbf{N}$ & Responders & \\
\hline Headache- complete recovery, day 7 & RR & 187 & 31 & 188 & 6 & $4.60[0.78 ; 27.15]$ \\
\hline Headache- complete recovery, day $2 \mathrm{I} \S$ & $\mathrm{RR}$ & 51 & 45 & 52 & 18 & $2.55[1.73 ; 3.75]$ \\
\hline Nasal discharge- complete recovery, day 7 & RR & 187 & 49 & 188 & 1 & $19.10[0.73 ; 497.35]$ \\
\hline Nasal discharge- complete recovery, day $21 \S$ & RR & 51 & 45 & 52 & 14 & $3.28[2.07 ; 5.19]$ \\
\hline Time until onset of treatment effect (days) & DM & 178 & & 163 & & $-1.44[-2.42 ;-0.47]$ \\
\hline Ability to go to work, day 7 & RR & 187 & 145 & 188 & 110 & $\mathrm{I} .4 \mathrm{I}[0.98 ; 2.0 \mathrm{I}]$ \\
\hline Paracetamol intake (500 mg tablets) & DM & 185 & & 188 & & $-0.24[-0.66 ; 0.17]$ \\
\hline IMOS, day 7 & DM & 186 & & 188 & & $-1.15[-2.23 ;-0.08]$ \\
\hline
\end{tabular}

\#DM-difference of means; values $<0$ favor EPs 7630

$\mathrm{RR}$ - risk ratio; values >I favor EPs 7630

§-Study 10 only

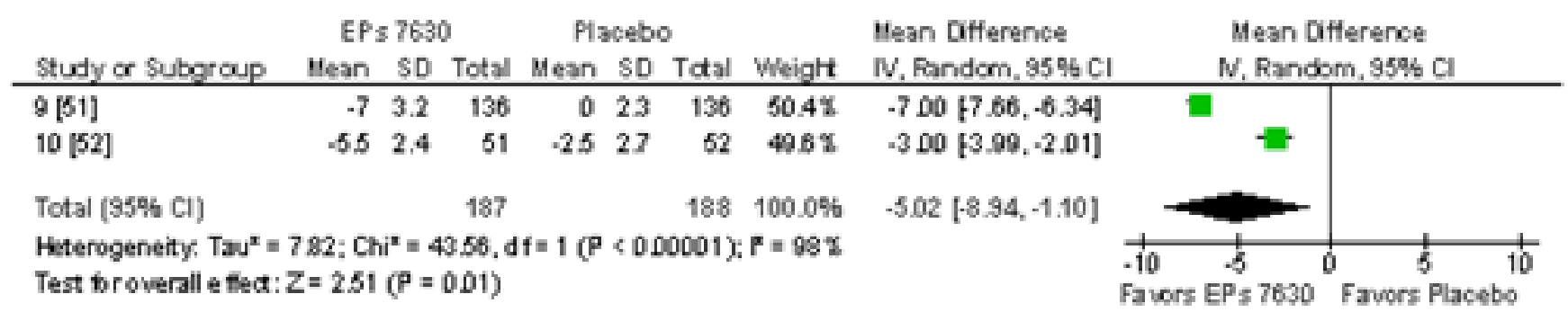

Figure 3 Meta-analysis of change of SSS total score between baseline and treatment day 7 in patients with acute rhino sinusitis.

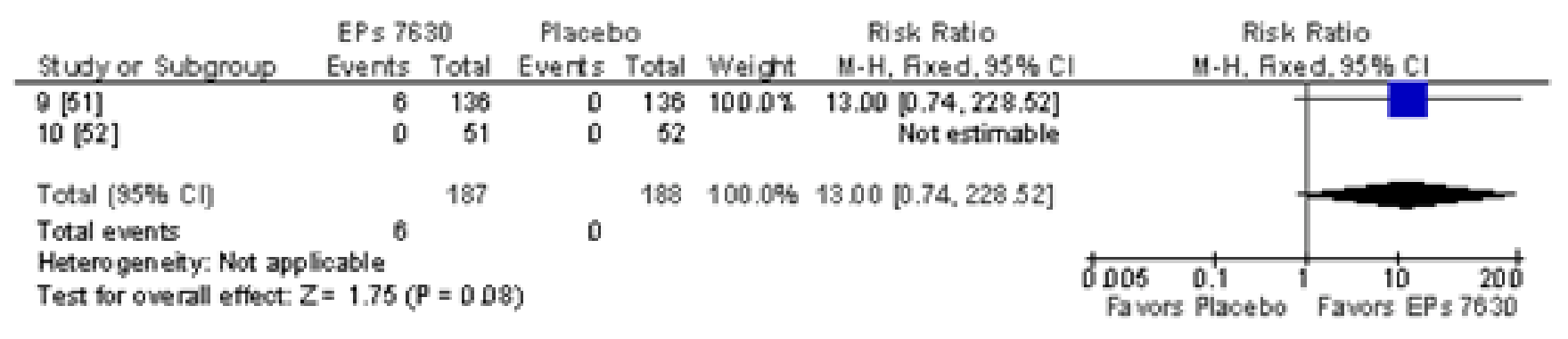

Figure 4 Meta-analysis of complete recovery of all symptoms assessed with the SSS until day 7 in patients with acute rhino sinusitis.

\section{Efficacy: Acute tonsillopharyngitis}

In ATP, the children treated with EPs 7630 showed a TSS total score reduction already after 4 days that was significantly more pronounced than in those who received placebo (Figure 5). The result is supported by a significant advantage of the herbal extract in the meta-analysis investigating complete symptom recovery at day 4 (Figure 6). Significant advantages for EPs 7630 were also observed for all other outcome measures for which meta-analyses were performed (Table 7), including a significantly lower use of paracetamol in the children treated with the herbal extract. 
Table 7 Meta-analysis results for outcome measures in acute tonsillopharyngitis based on studies no. 12 and 13

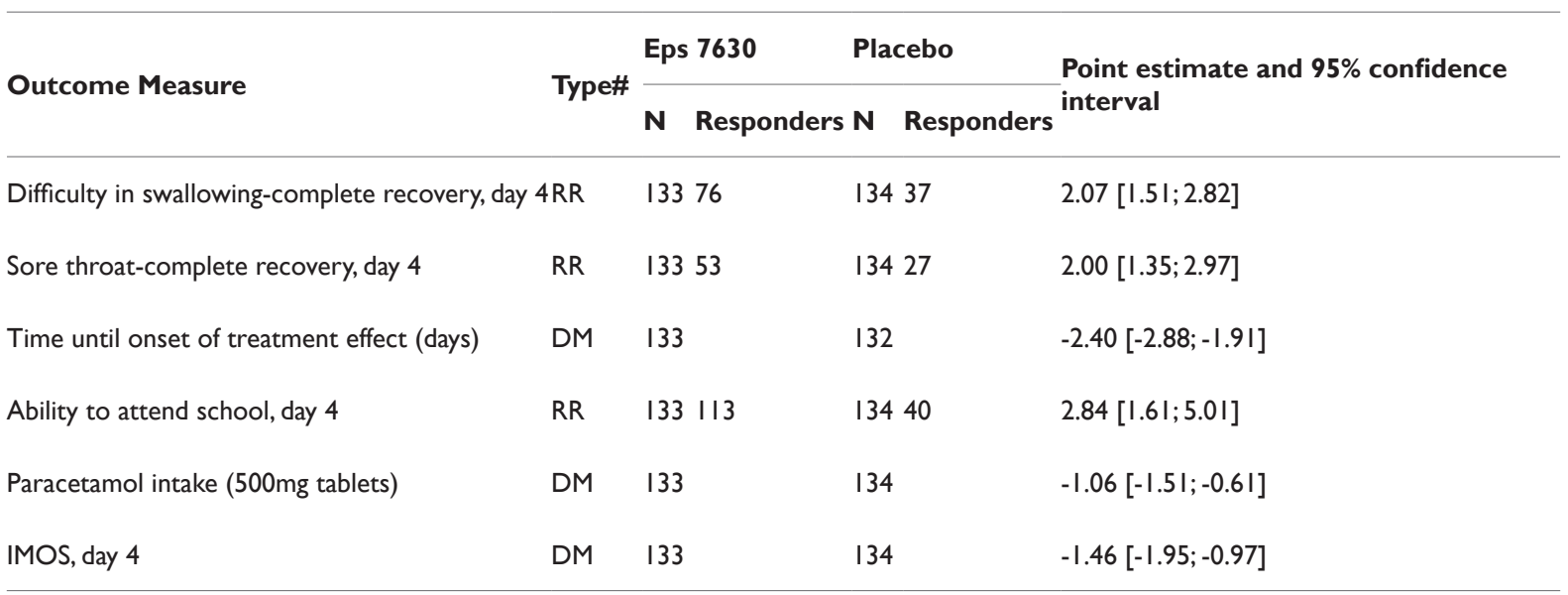

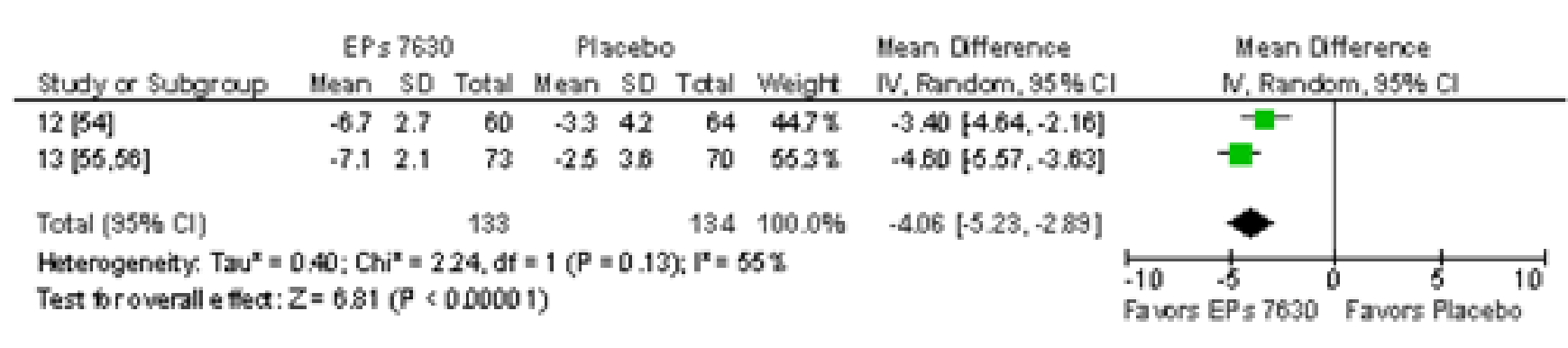

Figure 5 Meta-analysis of change of TSS total score between baseline and treatment day 4 in patients with acute tonsillopharyngitis.

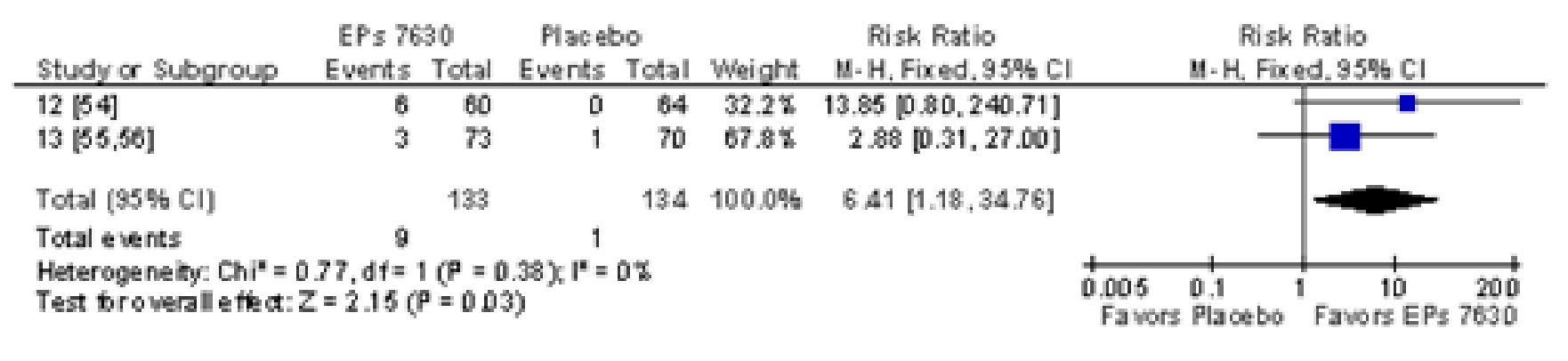

Figure 6 Meta-analysis of complete recovery of all symptoms assessed with the TSS until day 4 in patients with acute tonsillopharyngitis.

\section{Discussion}

Based on a total of 13 randomized, placebo-controlled, therapeutic clinical trials, this review of partially newly considered data shows that EPs 7630 is well tolerated, safe and efficacious in the treatment of AB, ARS, and ATP.

Our review of adverse events shows that for the event rates observed for the system groups listed in the Summary of Product Characteristics of the marketed products containing EPs 7630 were only slightly higher in patients treated with the herbal drug than in those who received placebo, and a risk increase by $1 \%$ or more could be excluded for all system groups except gastrointestinal complaints and epistaxis. These results are consistent with those of a comprehensive review of the safety and tolerability of EPs 7630 recently published by Matthys et al. [39] and based on data from 29 clinical trials and non-interventional studies (published and unpublished), with a total of more than 8,000 participants exposed to the herbal preparation. For most system groups, the authors found the type and incidence rate of adverse events observed in patients treated with EPs 7630 to be similar to the events reported in patients who received placebo, with only a slight increase of the risk of gastrointestinal disorders and epistaxis. For EPs 7630, these findings are also in accordance with safety results obtained in post-marketing surveillance studies performed in a larger patient population. ${ }^{39}$ The results therefore indicate that EPs 7630 is safe and well tolerated in clinical trials and under the general usage conditions in clinical practice alike.

With respect to treatment efficacy, the herbal drug was superior to placebo in supporting symptom relief and in improving the patients' over-all medical outcome in all 3 indications covered in our metaanalyses. Patients treated with EPs 7630 showed a faster onset of a perceived treatment effect, and the fact that the percentage of patients who were completely symptom-free at a pre-defined treatment day 
also indicates that the herbal drug shortened the duration of the disease. The latter interpretation is supported by the observation that patients treated with EPs 7630 were able to return to work, school, or kindergarten earlier than those exposed to placebo, which can be regarded as a significant contribution to easing the burden on the healthcare system as well as the economic impact of these trivial, yet very common conditions.

Scientific evidence for the efficacy of EPs 7630 was found to be strongest for $\mathrm{AB}$ where a total of 8 trials were eligible for review. It is remarkable that all placebo controlled trials showed significant superiority of the herbal extract for the pre-defined primary outcome measure of the original protocol, and although the studies performed in children and adolescents had not been designed and powered to demonstrate efficacy in subsets of patients defined by age, a proof of efficacy could nevertheless be achieved in our meta-analyses within the investigated subsets of children aged 1-5 and children and adolescents aged 6-18years. The validity of the results is also underlined by the fact that significant superiority of EPs 7630 over placebo was observed for most outcome measures investigated during our meta-analyses.

For ARS, evidence in adults was available for review whereas all trials in ATP were performed in children. For both indications our meta-analyses demonstrated efficacy of EPs 7630 in reducing both symptom severity and duration in the investigated target populations.

The results show that in the 3 indications investigated, symptom relief - as well as treatment group differences regarding the extent of symptom alleviation - were observable already at the pre-defined time points for the main efficacy analyses (AB, ARS: day 7; ATP: day 4) while the majority of the patients still had at least some residual symptoms remaining (with advantages for the herbal preparation). Acute respiratory tract infections are characterized by a complex clinical picture that includes a variety of specific and general symptoms, some of which may take weeks to subside completely. For example, coughing in $\mathrm{AB}$ may persist for at least 2 weeks after the initiation of treatment, ${ }^{40}$ and it is estimated that only about $45 \%$ of adult patients with ARS show complete recovery of all symptoms within 2 weeks after onset. ${ }^{41}$ The recovery rates in the trials included into this review are therefore consistent with the literature.

To date, 2 systematic reviews and meta-analyses of randomized, controlled clinical trials investigating the efficacy of Pelargonium sidoides extract in $\mathrm{RTIS}^{28-30}$ as well as 2 further reviews without formal meta-analyses ${ }^{17,42}$ have been published although, unlike our own work, none of them considered all therapeutic trials performed with EPs 7630: Agbabiaka and colleagues ${ }^{28,29}$ performed a review and meta-analysis of the efficacy and tolerability of EPs 7630 in AB into which studies no. 1, 2, 3, 5, and 6 of our review were included. Their meta-analysis of the BSS results revealed significant superiority of EPs 7630 over placebo in reducing the symptoms associated with $\mathrm{AB}$. The authors emphasized the high methodological quality of the primary trials and concluded that there is encouraging evidence that Pelargonium sidoides extract is efficacious in this indication.

The recently updated Cochrane review prepared by Timmer et al., ${ }^{30}$ assessed the efficacy of EPs 7630 in acute RTIs and identified studies no. $1,2,3,5,6,7$, and 8 for AB, study no. 10 for ARS, and study no. 13 for ATP. Studies no. 2 and 13 were excluded from their review for methodological reasons. Moreover, as the authors considered using the average symptom score change pre-specified in the original trial protocols as the primary outcome measure for describing the treatment effect not to be optimal in RTI, they performed a responder analysis during which they defined patients with symptoms not resolved at a pre-defined time to be responders. For the post-hoc redefined outcome measure, the main results of Timmer et al. ${ }^{30}$ metaanalyses in $\mathrm{AB}$ confirm superiority of EPs 7630 over placebo although the treatment effects were somewhat smaller than in the analysis performed by Agbabiaka et al. based on symptom score change. ${ }^{28,29}$

For AB, Timmer et al., ${ }^{30}$ also performed separate analyses for the liquid and the tablet formulations of EPs 7630 and concluded that the trials support the efficacy of EPs 7630 liquid formulation but not of the tablets. Our analyses show, however, that the effect sizes observed for the marketed strength of the tablet formulation (investigated in studies no. 5 and 7) were in the range of those of the liquid formulation. Trials no. 5 and 7 were dose-finding studies, each of which compared 3 different doses of EPs 7630 tablets to placebo. In Timmer et al., ${ }^{30}$ review these studies were entered into the meta-analyses as 3 separate trials each, assigning $1 / 3$ of the patients randomized to placebo to the control group for each of the EPs 7630 doses. From a methodological point of view we consider the arbitrary division of the placebo group, which resulted in a considerable loss of power in Timmer et al., ${ }^{30}$ metaanalyses, neither justified nor appropriate, and it is also debatable whether drug doses that were investigated in a dose-finding trial and were then not recommended according to the Summary or Product Characteristics of the drug should be included into an otherwise methodologically rigorous review with any scientific benefit. These discrepant procedures with regard to studies no. 5 and 7 explain the divergent results for the tablet formulation in Timmer et al., ${ }^{30}$ review as compared to ours.

Ulbricht et al.. ${ }^{42}$ as well as Moyo et al., ${ }^{17}$ reviewed randomized, controlled trials and observational studies with EPs 7630 without performing formal meta-analyses and concluded that the drug shows a beneficial effect in the treatment of acute RTIs, notably AB, ATP.

An advantage of this review is that both published and unpublished, randomized, placebo-controlled, therapeutic clinical trials with EPs 7630 were assessed for inclusion. Publication bias, that is an inherent threat to most systematic reviews, can therefore be excluded.

Clinical trials in self-limiting diseases like ATP and $\mathrm{AB}$ are difficult to perform because they require a careful timing of assessments so that a possible pharmacological treatment effect is not obscured by spontaneous remission. Our review suggests that the choices of a 7-day period for the treatment comparisons performed in $\mathrm{AB}$ and ARS as well as a 4-day period in ATP were appropriate as clinically meaningful differences between pharmacologically active and placebo treatment were observed.

In $\mathrm{AB}$, symptom severity was assessed in all trials using the BSS as a validated scale ${ }^{33,34}$ which has been shown to discriminate reliably between manifestations of bronchitis of different severities. ${ }^{32}$ Although in ARS and ATP no formal validations for the available scores have been published so far, our review demonstrates that the results obtained with the SSS and the TSS showed a high degree of concordance with other symptom related efficacy measures like the IMOS (as a global rating of clinical outcome), time until the onset of a meaningful treatment effect, and the ability to go to work or attend school or kindergarten.

\section{Conclusions}

This systematic review and meta-analysis shows encouraging evidence for the efficacy and safety of Pelargonium sidoides extract EPs 7630 in children and adults with $\mathrm{AB}$ as well as in adult patients 
with ARS and in children with ATP. Compared to placebo patients treated with the herbal extract showed a faster onset of remission, reduced symptom severity and duration as well as an earlier return to work, school, or kindergarten. The results also confirm that EPs 7630 is a well-tolerated herbal medicine in the management of acute RTIs in children, adolescents and adults.

\section{Acknowledgements}

Medical writing services were provided by Dr. Andreas Völp, Psy Consult Scientific Services, Frankfurt, Germany. This work, including provision of all trial data used in this article, was supported by Dr. Willmar Schwabe GmbH \& Co. KG, Karlsruhe, Germany.

\section{Conflict of interest}

HM, WL and WK received honoraria from Dr. Willmar Schwabe GmbH \& Co. KG, Karlsruhe, Germany. AZ and JB are employees of Dr. Willmar Schwabe GmbH \& Co. KG, Karlsruhe, Germany.

\section{References}

1. File TM. The epidemiology of respiratory tract infections. Semin Respir Infect. 2000;15(3):184-194.

2. Garibaldi RA. Epidemiology of community-acquired respiratory tract infections in adults. Incidence, etiology, and impact. Am J Med. $1985 ; 78(6 \mathrm{~B}): 32-37$

3. Monto AS. Epidemiology of viral respiratory infections. Am $\mathrm{J} \mathrm{Med}$. 2002;112(6A):4S-12S

4. Van Gageldonk Lafeber AB, Van der Sande MA, Heijnen ML, et al. Risk factors for acute respiratory tract infections in general practitioner patients in The Netherlands: a case-control study. BMC Infect Dis. 2007;7:35.

5. Manoharan A, Winter J. Tackling upper respiratory tract infections. Practitioner. 2010;254(1734):25-28, 22-23.

6. Verheij T, Hermans J, Kaptein A, et al. Acute bronchitis: course of symptoms and restrictions in patients' daily activities. Scand J Prim Health Care. 1995;13(1):8-12.

7. Birnbaum HG, Morley M, Greenberg PE, et al. Economic burden of respiratory infections in an employed population. Chest. 2002;122(2):603-611

8. Bertino JS. Cost burden of viral respiratory infections: issues for formulary decision makers. Am J Med. 2002;112(6A):42S-49S.

9. Mostov PD. Treating the immunocompetent patient who presents with an upper respiratory infection: pharyngitis, sinusitis, and bronchitis. Prim Care. 2007;34(1):39-58.

10. Niroumand M, Grossman RF. Airway infection. Infect Dis Clin North Am. 1998;12(3):671-688.

11. Dreschers S, Franz P, Dumitru CA, et al. Infections with human rhinovirus induce the formation of distinct functional membrane domains. Cell Physiol Biochem. 2007;20(1-4):241-254.

12. Kempen VM, Bachert C, Van Cauwenberge P. An update on the path physiology of rhinovirus upper respiratory tract infections. Rhinology. 1999;37(3):97-103.

13. Fahey T, Howie J. Re-evaluation of a randomized controlled trial of antibiotics for minor respiratory illness in general practice. Fam Pract. 2001;18(3):246-248.

14. Williamson HA Jr. A randomized, controlled trial of doxycycline in the treatment of acute bronchitis. J Fam Pract. 1984;19(4):481-486.
15. Carroll KC. Laboratory diagnosis of lower respiratory tract infections:controversy and conundrums. J Clin Microbiol. 2002;40(9):31153120 .

16. Linder JA, Singer DE, Stafford RS. Association between antibiotic prescribing and visit duration in adults with upper respiratory tract infections. Clin Ther. 2003;25(9):2419-2430.

17. Moyo M, Van Staden J. Medicinal properties and conservation of Pelargonium sidoides DC. J Ethnopharmacol. 2014;152(2):243-255.

18. Kayser O, Kolodziej H, Kiderlen AF. Immunomodulatory principles of Pelargonium sidoides. Phytother Res. 2001;15(2):122-126.

19. Kolodziej H. Fascinating metabolic pools of Pelargonium sidoides and Pelargonium reniforme, traditional and phytomedicinal sources of the herbal medicine Umckaloabo. Phytomedicine. 2007;14(6):9-17.

20. Kolodziej H, Kayser O, Radtke OA, et al. Pharmacological profile of extracts of Pelargonium sidoides and their constituents. Phytomedicine. 2003;10(4):18-24.

21. Kolodziej H, Kiderlen AF. In vitro evaluation of antibacterial and immunomodulatory activities of Pelargonium reniforme, Pelargonium sidoides and the related herbal drug preparation EPs 7630. Phytomedicine. 2007;14(6):18-26.

22. Conrad A, Hansmann C, Engels I, et al. Extract of Pelargonium sidoides (EPs 7630) improves phagocytosis, oxidative burst, and intracellular killing of human peripheral blood phagocytes in vitro. Phytomedicine. 2007;14(6):46-51.

23. Conrad A, Jung I, Tioua D, et al. Extract of Pelargonium sidoides $(E P s ® 7630)$ inhibits the interactions of group A-streptococci and host epithelia in vitro. Phytomedicine. 2007;14(6):52-59.

24. Rezaizadehnajafi L, Wink M. EPs 7630(®) from Pelargonium sidoides increases stress resistance in Caenorhabditis elegans probably via the DAF-16/FOXO pathway. Phytomedicine. 2014;21(4):547-550.

25. Helfer M, Koppensteiner H, Schneider M, et al. The root extract of the medicinal plant pelargonium sidoides Is a Potent HIV-1 Attachment Inhibitor. PloS one. 2014;9(1):e87487.

26. Michaelis M, Doerr HW, Cinatl J. Investigation of the influence of EPs ${ }^{\circledR} 7630$, a herbal drug preparation from Pelargonium sidoides, on replication of a broad panel of respiratory viruses. Phytomedicine. 2011;18(5):384-386.

27. Theisen LL, Muller CP. EPs ${ }^{\circledR} 7630$ (Umckaloabo ${ }^{\circledR}$ ), an extract from Pelargonium sidoides roots, exerts anti-influenza virus activity in vitro and in vivo. Antiviral Res. 2012;94(2):147-156.

28. Agbabiaka TB, Guo R, Ernst E. Pelargonium sidoides for acute bronchitis: a systematic review and meta-analysis. Phytomedicine. 2008;15(5):378-385.

29. Agbabiaka TB, Guo R, Ernst E. Erratum to "Pelargonium sidoides for acute bronchitis: A systematic review and meta-analysis" [Phytomedicine 15 (2008) 378-385]. Phytomedicine. 2009;16(8):798-799.

30. Timmer A, Gunther J, Motschall E, et al. Pelargonium sidoides extract for treating acute respiratory tract infections. Cochrane Database Syst Rev. 2013;10:Cd006323.

31. Committee on Herbal Medicinal Products (HMPC). Assessment report on Pelargonium sidoides DC and/or Pelargonium reniforme Curt., radix. European Medicines Agency, London, UK; 2012.

32. Matthys H, Kamin W. Positioning of the Bronchitis Severity Score (BSS) for standardised use in clinical studies. Curr Med Res Opin. 2013;29(10):1383-1390.

33. Kardos P, Lehrl S, Kamin W, et al. Assessment of the effect of pharmacotherapy in common cold/acute bronchitis - the Bronchitis Severity Scale (BSS). Pneumologie. 2014;68(8):542-546. 
34. Lehrl S, Matthys H, Kamin W, et al. The BSS-a valid clinical instrument to measure the severity of acute bronchitis. J Lung Pulm Respir Res. 2014;1(3):00016.

35. Steinsbekk A. The Data Collection Group Data Collection in Homeopathic Practice. A Proposal for an International Standard. European Committee for Homeopathy; 1999.

36. Review Manager (Rev Man). Version 5.2 [Computer Program]. The Nordic Cochrane Centre, the Cochrane Collaboration, Copenhagen; 2012 .

37. Newcombe RG. Two-sided confidence intervals for the single proportion:comparison of seven methods. Stat Med. 1998;17 (8):857-872.

38. Newcombe RG. Interval estimation for the difference between independent proportions: comparison of eleven methods. Stat Med. 1998;17(8):873-890

39. Matthys H, Köhler S, Kamin W. Safety and tolerability of EPs 7630 in clinical trials. Adv Pharmacoepidemiol Drug Saf. 2013; 2(4):142.

40. Worrall G. Acute bronchitis. Can Fam Physician. 2008;54(2):238-239.

41. Aring AM, Chan MM. Acute rhino sinusitis in adults. Am Fam Physician. 2011;83(9):1057-1063.

42. Ulbricht C, Abrams TR, Conquer J, et al. An evidence-based systematic review of umckaloabo (Pelargonium sidoides) by the Natural standard research collaboration. J Diet Suppl. 2010;7(3):283-302.

43. Chuchalin AG, Berman B, Lehmacher W. Treatment of acute bronchitis in adults with a pelargonium sidoides preparation (EPS $\left.{ }^{\circledR} 7630\right)$ : randomized, double-blind, placebo-controlled trial. Explore (NY). 2005;1(6):437-445.

44. Matthys H, Eisebitt R, Seith B, et al. Efficacy and safety of an extract of Pelargonium sidoides (EPs 7630) in adults with acute bronchitis. A randomised, double-blind, placebo-controlled trial. Phytomedicine. 2003;10(4):7-17.

45. Matthys H, Heger M. Treatment of acute bronchitis with a liquid herbal drug preparation from Pelargonium sidoides (EPs 7630):a randomised, double-blind, placebo-controlled, multicentre study. Curr Med Res Opin. 2007;23(2):323-331.

46. Efficacy of EPs 7630 solution in the treatment of acute bronchitis in adults. Internal report (unpublished). Dr. Willmar Schwabe GmbH \& Co. KG, Karlsruhe, Germany; 2004.
47. Matthys H, Lizogub VG, Malek FA, et al. Efficacy and tolerability of EPs 7630 tablets in patients with acute bronchitis:a randomised, double-blind, placebo-controlled dose-finding study with a herbal drug preparation from Pelargonium sidoides. Curr Med Res Opin. 2010;26(6):1413-1422.

48. Kamin W, Maydannik V, Malek FA, et al. Efficacy and tolerability of EPs 7630 in children and adolescents with acute bronchitis-a randomized, double-blind, placebo-controlled multicenter trial with a herbal drug preparation from Pelargonium sidoides roots. Int J Clin Pharmacol Ther. 2010;48(3):184-191.

49. Kamin W, Maydannik VG, Malek FA, Kieser M. Efficacy and tolerability of EPs 7630 in patients (aged 6-18years old) with acute bronchitis - a randomized, double-blind, placebo-controlled clinical dose-finding study. Acta Paediatr. 2010;99(4):537-543.

50. Kamin W, Ilyenko LI, Malek FA, et al. Treatment of acute bronchitis with EPs 7630:randomized, controlled trial in children and adolescents. Pediatr Int. 2012;54(2):219-226.

51. Bachert C, Schapowal A. EPs ${ }^{\circledR} 7630$ (Extrakt aus Pelargonium sidoides) ist wirksam in der Behandlung der akuten Sinusitis maxillaris Ergebnisse zweier doppelblinder, placebokontrollierter Studien. Z Phytother 26 (Kongressband Phytopharmaka Phytotherapie). 2005;S4.

52. Bachert C, Schapowal A, Funk P, et al. Treatment of acute rhinosinusitis with the preparation from Pelargonium sidoides EPs 7630:a randomized, double-blind, placebo-controlled trial. Rhinology. 2009;47(1):51-58.

53. Efficacy of EPs 7630 for acute angina catarrhalis. Internal report (unpublished). Dr Willmar Schwabe GmbH \& Co. KG, Karlsruhe, Germany; 1999.

54. Joseph G. Wirksamkeit von EPs 7630 bei akuter Angina catarrhalis. Internal report (unpublished). Dr. Willmar Schwabe GmbH \& Co. KG, Karlsruhe, Germany; 2003.

55. Heger M, Bereznoy VV. Tonsillopharyngitis in children not caused by streptococci: Efficacy of an extract from Pelargonium sidoides (EPs 7630 ) in comparison with placebo [in German]. In:Schulz V et al. (Eds) Phytopharmaka in Forschung und klinischer Anwendung, Vol. VII. Steinkopff, Darmstadt, Germany; 2002. p. 13-25.

56. Bereznoy VV, Riley DS, Wassmer G, et al. Efficacy of extract of Pelargoinium sidoides in children with acute non-group A beta-hemolytic streptococcus tonsillopharyngitis:a randomized, double-blind, placebo-controlled trial. Altern Ther Health Med. 2003;9(5):68-79. 